\title{
PENGARUH PELAKSANAAN PERENCANAAN PULANG TERHADAP KEPUASAN PASIEN
}

\author{
${ }^{1}$ Aminuddin \\ ${ }^{1}$ Dosen Poltekkes Kemenkes Palu \\ e-mail: aminuddinraihan@yahoo.com
}

\begin{abstract}
Abstrak
Tujuan penelitian adalah untuk mengetahui pengaruh pelaksanaan perencanaan pulang terhadap kepuasan pasien di ruang Flamboyan dan Seroja RSUD Undata Palu. Jenis penelitian adalah analitik dengan pendekatan pra eksperimental. Jumlah sampel 10 orang masing-masing 5 pasien di ruang Falmboyan sebagai kelompok intervensi dan 5 pasien di ruang Seroja sebagai kelompok kontrol. Hasil penelitian menunjukkan kepuasan pasien pada kelompok intervensi mengatakan puas sebanyak 5 orang responden (100\%), sedangkan pada kelompok kontrol responden mengatakan cukup puas 4 orang $(80 \%)$ dan yang mengatakan puas 1 orang $(20 \%)$. Pada uji $t$ tes untuk dua sampel kecil tidak saling berhubungan diperoleh nilai $t_{0}=7,264$ dibandingkan dengan nilai $t_{\text {tabel }}$ pada taraf signifikans $5 \%$, nilai $t_{\text {tabel }}=2,11$. Nilai $t_{0}$ lebih besar dari pada nilai $t_{\text {tabel }}$, maka terdapat perbedaan kepuasan pasien yang dilakukan perencanaan pulang antara kelompok intervensi dengan kontrol. Disarankan bagi pihak RSUD Undata Palu agar pelaksanaan perencanaan pulang dapat diterapkan pada setiap ruang perawatan untuk mengoptimalkan kualitas pelayanan yang diberikan.
\end{abstract}

Kata kunci: Pelaksanaan perencanaan pulang, kepuasan, pasien

\begin{abstract}
The research objective was to determine the effect of discharge planning on patient satisfaction in the flamboyan and seroja room at RSUD Undata in the city Palu. This type of research is an experimental pre-analytic approach. Number of samples 10 each 5 patients in the room Falmboyan as the intervention group and 5 patients in the room Seroja as the control group. Results showed patient satisfaction in the intervention group says satisfied by 5 respondents (100\%), while the control group of respondents reported being very satisfied 4 people $(80 \%)$ and that said one person satisfied (20\%). In the test sample t test for two small unrelated obtained value $t_{0}=7,264$ compared with ttable value at the level of significance of $5 \%$, the value $t_{\text {table }}=2,11 . t_{0}$ value is greater than the value $t_{\text {table }}$ then there are differences in patient satisfaction do discharge planning between the intervention group with the control. It is advisable for the hospitals Undata Palu that discharge planning can be applied to the treatment room to optimize the quality of services provided.
\end{abstract}

Keywords: Implementation of discharge planning, satisfaction, patient

\section{PENDAHULUAN}

Kepuasaan pasien sebagai salah satu indikator pelayanan berkualitas harus menjadi perhatian karena berhubungan langsung dengan pengguna pelayanan kesehatan (Herniyatun, 2009). Kepuasan dirasakan oleh pasien dimulai dari pertama kali datang sampai pasien meninggalkan rumah sakit. Perawat sebagai ujung tombak pelayanan terhadap pasien dan keluarganya di rumah sakit, karena frekuensi pertemuannya dengan pasien yang paling sering (Anjaryani, 2009). Proses keperawatan merupakan rangkaian tindakan asuhan keperawatan yang harus dilakukan perawat secara sistematis, berkesinambungan, terencana dan profesional (Asmadi, 2012). Proses dinamis perencanaan pulang memberi kesempatan bagi tenaga kesehatan untuk menyiapkan pasien melakukan perawatan mandiri di rumah (Nursalam, 2014). 
Hasil studi pendahuluan yang dilakukan oleh peneliti di RSUD Undata Palu diruang Flamboyan dan Seroja pada bulan Januari 2015 didapatkan hasil bahwa pelaksanaan perencanaan pulang belum pernah dilakukan di ruangan tersebut, karena format untuk perencanaan pulang belum tersedia, demikian pula yang dikatakan pasien yang dirawat di ruangan bahwa kalau mereka akan pulang tidak dijelaskan apa yang harus dilakukan di rumah setelah dirawat di Rumah Sakit. Perencanaan Pulang merupakan suatu proses yang dinamis dan sistematis dari penilaian, persiapan, serta koordinasi yang dilakukan untuk memberi kemudahan pengawasan pelayanan kesehatan dan pelayanan sosial sebelum dan sesudah pasien pulang (Nursalam, 2014).

Manfaat perencanaan pulang; memberi kesempatan kepada pasien untuk mendapatkan pelajaran selama di Rumah Sakit sehingga bisa dimanfaatkan sewaktu dirumah, tindak lanjut yang sistematis yang digunakan untuk menjamin kontinuitas keperawatan pasien, mengevaluasi pengaruh dari intervensi yang terencana pada penyembuhan pasien dan mengidentifikasi kekambuhan atau kebutuhan keperawatan baru, membantu kemandirian pasien dalam kesiapan melakukan keperawatan di rumah.

Kepuasan adalah perasaan senang atau kecewa seseorang yang muncul setelah membandingkan antara persepsi atau kesannya terhadap kinerja atau hasil suatu produk dan harapan-harapan (Nursalam 2014). Faktor-faktor penyebab ketidakpuasan pelanggan; tidak sesuainya harapan dan kenyataan, layanan selama proses menikmati jasa tidak memuaskan, perilaku personel kurang memuaskan, suasana dan kondisi fisik lingkungan tidak menunjang, biaya terlalu tinggi, jarak terlalu jauh, banyak waktu yang terbuang dan harga yang tidak sesuai, promosi atau iklan tidak sesuai dengan kenyataan.

\section{METODE PENELITIAN}

Jenis penelitian ini adalah penelitian analitik dengan metode penelitian quasieksperimen. Desain yang digunakan dalam penelitian ini adalah pra eksperimental dengan jenis perbandingan kelompok statis (static group comparison), dalam rancangan penelitian ini kelompok eksperimen menerima perlakuan $(X)$ yang diikuti dengan pengukuran kedua atau observasi. Hasil observasi ini kemudian dibandingkan dengan hasil observasi pada kelompok kontrol yang tidak diberi perlakuan.

Tujuan rancangan penelitian ini untuk melihat perbedaan kepuasan pasien pada kelompok yang diberi perlakuan dengan kelompok yang tidak diberikan perlakuan (kontrol). Dalam hal ini untuk kelompok perlakuan yaitu pasien yang dirawat di ruang Flamboyan sedangkan kelompok kontrol yaitu pasien yang dirawat di ruang Seroja. Ruangan Flamboyan dan Seroja merupakan ruangan penyakit dalam dengan kelas dan pelayanan yang sama. Skema desain penelitian dapat digambarkan sebagai berikut:

Bagan 1. Skema Desain Penelitian

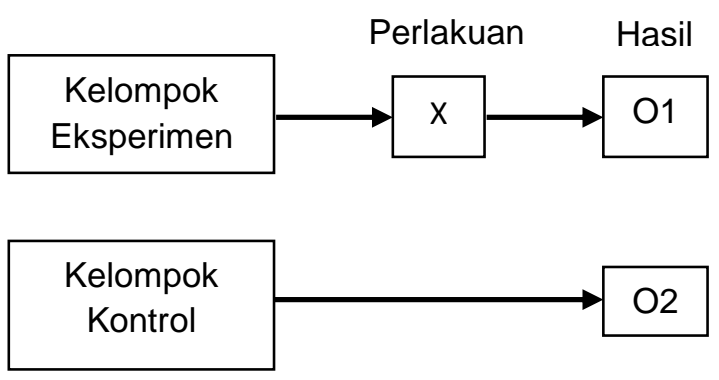

Keterangan :

$\mathrm{X}$ : Perlakuan, pelaksanaan perencanaan pulang oleh perawat.

O1 : Tingkat kepuasan pasien yang

dilakukan perencanaan pulang.

O2 : Tingkat kepuasan pasien yang tidak dilakukan perencanaan pulang.

Sampel dalam penelitian ini berjumlah 10 orang pasien yang dirawat diruang Flamboyan dan Seroja. Masing-masing 5 orang pasien sebagai kelompok perlakuan dan 5 orang pasien sebagai kelompok kontrol. Pemilihan sampel dilakuak dengan purposive sampling. Analisis data yang digunakan dalam penelitian ini adalah uji $\mathrm{T}$ tes berpasangan karena memenuhi syarat: data berdistribusi secara normal, kedua kelompok 
data independen, dan variabel yang diuji berbentuk numeric.

\section{HASIL PENELITIAN}

Populasi dalam penelitian ini berjumlah 10 orang pasien, 5 orang pasien yang dirawat di ruang Flamboyan sebagai kelompok intervensi dan 5 orang pasien yang dirawat diruang Seroja sebagai kelompok kontrol.

Kepuasan pasien pada kelompok intervensi mengatakan puas sebanyak 5 orang responden yakni $100 \%$. Kepuasan pasien pada kelompok kontrol sebagian besar mengatakan cukup puas sebanyak 4 orang $(80 \%)$ dan yang mengatakan puas 1 orang $(20 \%)$.

Perbedaan kepuasan pasien yang dilakukan perencanaan pulang dan yang tidak dilakukan perencanaan pulang. Nilai : $\sum x^{2}=$ 9,2; $\quad \Sigma y^{2}=18,8$ dan $\mathrm{N}=5$, dengan menggunakan rumus " $\mathrm{t}$ " tes untuk dua sampel kecil yang tidak saling berhubungan diperoleh nilai $t_{0}=7,264$. Dengan df sebesar 8 kita melihat nilai " $\mathrm{t}$ ", pada taraf signifikansi $5 \%$ dengan nilai $t_{\text {tabel }}=2,11$. Sehingga nilai $t_{0}=$ 7,264 lebih besar dari $t_{\text {tabel }}=2,11$. taraf signifikansi $1 \% t_{\text {tabel }}=2,90 \cdot t_{0}=7,264$ lebih besar dari $t_{\text {tabel }}=2,90$. Berdasarkan hasil di atas maka $H_{0}$ ditolak, atau ada pengaruh pelaksanaan perencanaan pulang terhadap kepuasan pasien di ruang Flamboyan dan Seroja RSUD Undata Palu.

\section{PEMBAHASAN}

\section{Kepuasan Pasien yang Dilakukan Perencanaan Pulang}

Menurut asumsi peneliti, pasien mengatakan puas pada kelompok intervensi karena pasien dilakukan sesuai dengan standar pada perencanaan pulang seperti: menyambut kedatangan pasien, memberikan orientasi ruangan, menjelaskan peraturan dan denah ruangan, memperkenalkan pasien pada teman sekamar, perawat dokter atau tenaga kesehatan lain. Pada persiapan pulang perawat memberikan penjelasan mengenai aturan diet, pendidikan kesehatan, pengaturan obat serta perawatan yang dilakukan dirumah sehingga perawat terkesan ramah dan bersahabat dan pasien merasa diperhatikan.
Didukung oleh teori yang menyatakan kepuasan merupakan perasaan seseorang yang muncul sebagai hasil dari membandingkan harapan dengan kenyataan yang dialami. Pasien akan terpuaskan jika tidak ada selisih antara kondisi yang dibutuhkan dengan kondisi aktual. Semakin besar kekurangan dari hal yang dibutuhkan, maka semakin besar rasa ketidakpuasan (Herniyatun, 2009)

Sejalan dengan tujuan perencanaan pulang yaitu untuk meminimalkan dampak dari suatu penyakit dengan perawatan yang kontinu (terus menerus) dari pertama kali pasien datang sampai pasien meninggalkan rumah sakit serta untuk meningkatkan kepuasan pasien dan keluarga terhadap sistem pelayanan kesehatan (Hariyati, 2008).

\section{Kepuasan Pasien yang tidak Dilakukan Perencanaan Pulang}

Kepuasan pasien pada kelompok kontrol sebagian besar mengatakan cukup puas sebanyak 4 orang $(80 \%)$ sedangkan yang mengatakan puas 1 orang (20\%). Menurut peneliti, pasien cukup puas pada kelompok kontrol disebabkan oleh kepuasan pasien bersifat relatif, selain itu pasien tidak memperhatikan apakah tindakan yang diberikan adalah perencanaan pulang atau tindakan rutinitas perawat saja diruangan. Dalam perencanaan pulang diperlukan komunikasi yang baik, terarah, diberikan secara lisan maupun tertulis sehingga apa yang disampaikan dapat dimengerti dan berguna untuk proses perawatan ketika pasien kembali kerumah.

Menurut teori Yosafianti dan Alfiyanti, (2010), kepuasan pasien dipengaruhi oleh faktor internal yaitu karakteristik individual pasien dan faktor ekternal yaitu pelayanan kesehatan yang berasal dari rumah sakit termasuk pelayanan keperawatan

Teori Utama (2003), bahwa kepuasan tidak hanya dipengaruhi oleh faktor dari pihak pemberi pelayanan saja, tetapi juga dipengaruhi faktor dari luar maupun dari dalam diri pasien. Faktor dari dalam mencakup sumber daya, pendidikan, pengetahuan dan sikap. Faktor dari luar 
mencakup budaya, sosial ekonomi, keluarga dan situasi yang dihadapi. Faktor-faktor dasar yang mempengaruhi kepuasan yaitu; pengetahuan, kesadaran, sikap positif, sosial ekonomi, sistem nilai, pemahaman pasien tentang jenis pelayanan yang akan diterimanya (tingkat pemahaman pasien terhadap tindakan yang diberikan akan mempengaruhi tingkat kepuasan seseorang terhadap tindakan) dan empati yang ditujukan oleh pemberi pelayanan kesehatan, sikap ini akan menyentuh emosi pasien. Faktor - faktor inilah yang akan berpengaruh terhadap kepuasan pasien tentang pelayanan yang diberikan.

Teori yang sama oleh Nursalam (2014), faktor penyebab ketidakpuasan pasien terhadap pelayanan yang diberikan yaitu pelayanan tidak sesuai harapan, selama proses perawatan pasien tidak menikmati jasa yang diberikan, kepribadian, sikap, tutur kata yang kurang baik, suasana dan kondisi fisik lingkungan tidak menunjang, biayaterlalu tinggi, jarak terlalu jauh, banyak waktu yang terbuang, harga yang tidak sesuai, kinerja perawat tidak memuaskan, kinerja ini adalah kecepatan, kemudahan, dan kenyamanan bagaimana perawat dalam memberikan jasa terutama dalam memberikan pelayanan keperawatan.

\section{Perbedaan Kepuasan Pasien Antara Kelompok Intervensi dengan Kelompok Kontrol}

Adanya perbedaan kepuasan pasien yang dilakukan perencanaan pulang dan yang tidak dilakukan perencanaan pulang disebabkan oleh kemudahan pasien dan keluarga mendapatkan informasi, perilaku dan tutur kata perawat yang sopan, kepribadian yang baik, serta keramahan perawat sehingga pasien merasa mendapatkan pelayanan kesehatan yang lebih maksimal serta diperlakukan sesuai bahkan lebih dari yang diharapkan, sebaliknya pada pasien yang tidak diakukan perencanaan pulang pasien merasa kurang diperhatikan, perawat terkesan cuek terhadap masalah yang dhadapi pasien, pasien tidak mengetahui tentang penyakit, diet yang harus dipatuhi, jadwal kontrol kembali serta hal-hal yang dapat memicu kekembuhan sehingga pasien kembali di rawat di Rumah Sakit dengan kasus yang sama bahkan tidak jarang disertai komplikasi.

Sejalan dengan teori Rosyidi (2013), perencanaan pulang adalah masalah multidisiplin atau interaksi. Ini adalah proses dimana profesional perawatan kesehatan, pasien dan keluarga berkolaborasi untuk memberikan dan mengatur kontinuitas perawatan yang diperlukan pasien. Perencanaan harus berpusat pada masalah pasien, yaitu pencegahan, terapeutik, rehabilitatif dan perawatan yang terusmenerus.

Hasil penelitian ini juga didukung oleh teori Nursalam (2014), kepuasan pasien terjadi apabila apa yang menjadi kebutuhan, keinginan, harapan pasien dapat dipenuhi atau sesuai bahkan melebihi harapan. Kepuasan pasien dipengaruhi oleh beberapa faktor yaitu; kualitas produk atau jasa,; kinerja, wujud dari kinerja ini adalah kecepatan, kemudahan, dan kenyamanan, kemudahan dalam memenuhi kebutuhan pasien keramahan,; estetika merupakan daya tarik Rumah Sakit yang dapat ditangkap oleh panca indra konsumen misalnya keramahan petugas kesehatan,; pelayanan, yakni kecepatan dalam pelayanan. Institusi pelayanan kesehatan dianggap baik apabila dalam memberikan pelayanan lebih memperhatikan kebutuhan pasien,; dan komunikasi, misalnya keluhan-keluhan dari pasien dengan cepat diterima oleh perawat.

Teori yang sama Nursalam (2014) survei kepuasan harus mempertimbangkan aspek apa saja yang dinilai pasien. Karakteristik yang digunakan oleh pasien dalam mengevaluasi kualitas jasa layanan, antara lain: kenyataan, yaitu berupa penampilan fasilitas fisik,; empati yaitu kesediaan perawat untuk memberikan perhatian secara pribadi kepada pasien,; cepat tanggap, yaitu kemauan dari perawat untuk membantu pasien dengan cepat serta mendengar dan mengatasi keluhan dari pasien,; keandalan yaitu kemampuan untuk memberikan jasa sesuai dengan yang dijanjikan, terpercaya , 
akurat dan konsisten,; dan kepastian, yaitu berupa kemampuan perawat untuk menimbulkan keyakinan dan kepercayaan terhadap janji yang telah dikemukakan kepada konsumen.

\section{KESIMPULAN}

Kesimpulan penelitian ini semua pasien pada kelompok intrevensi mengatakan puas sedangkan pada kelompok kontrol sebagian besar pasien mengatakan cukup puas sehingga ada perbedaan kepuasan pasien yang dilakukan perencanaan pulang dan yang tidak dilakukan perencanaan pulang

\section{SARAN}

Disarankan bagi pihak RSUD Undata Palu agar pelaksanaan perencanaan pulang dapat diterapkan pada setiap ruang perawatan untuk mengoptimalkan kualitas pelayanan yang diberikan.

\section{Daftar Pustaka}

Anjaryani, D., (2009). Kepuasan Pasien

Rawat Inap Terhadap Pelayanan Perawat di RSUD Tugurejo Semarang, (Online). (http://download.portalgaruda.org diakses 01 November 2015.

Asmadi. 2012. Konsep Dasar Keperawatan.

Penerbit buku kedokteran. EGC: Jakarta.
Darmawan, D., (2013). Metode Penelitian Kuentitatif. PT Remaja Rosdakarya Offiset : Bandung.

Hariyati, dkk., (2008). Evaluasi Model Perencanaan Pulang yang BerbasisTeknologi Informasi (Online). http://journal.ui.ac.id diakses 01 September 2015.

Herniyatun, dkk., (2009). Efektivitas Program Discharge Planning Terhadap Tingkat Kepuasan Pasien di Rumah Sakit Umum Daerah Kabupaten Kebumen, (Online). (http://ejournal.stikesmuhgombong.ac.id diakses 01 September 2015 )

Notoatmojo, S., (2012). Metodologi Penelitian Kesehatan. PT RINEKA CIPTA : Jakarta.

Nursalam, (2014). Manajemen Keperawatan. Aplikasi dalam Praktik Keperawatan Profesional Selemba Medika : Jakarta.

Rosyidi, K., (2013). Manajemen Keperawatan dalam Keperawatan. TIM : Jakarta.

Utama, S., (2003). Memahami Fenomena Kepuasan Pasien Rumah Sakit Referensi Pendukung Untuk Mahasiswa, Akademik, Pimpinan, Organisasi, dan Praktisi Kesehatan, (Online). http://digilib.unimus.ac.id diakses 08 juli 2015 